\title{
Improving Emotional Intelligence (EI) using Neuro Linguistic Programming (NLP) techniques
}

\author{
Kamarul Zaman Ahmad \\ University of Dubai \\ E-mail:kbinahmad@ud.ac.ae
}

\begin{abstract}
Since, Ahmad (2011) who looked at the effectiveness of the alternative techniques of NLP, Time Line Therapy®, and Hypnosis, there has been no further research regarding the effectiveness of NLP. This study improves the said research by ensuring that most of the respondents were not self-selected and ensured the use of other NLP techniques, in the context of improving EI. Although there are many self-development training courses advertised on the internet claiming to be able to improve EI, yet no credible research has been published in peer-reviewed academic journals to show whether such techniques can improve EI. This experimental research involved 35 test subjects and 35 control group subjects. Statistical $t$-tests revealed that with the test group, there were significant improvements in EI scores after undergoing the training compared with before. There were no significant changes in the control group.
\end{abstract}

Keywords: Emotional Intelligence, Neuro Linguistic Programming, Experiments 


\section{INTRODUCTION}

There is an increasing interest in the topic of emotional intelligence (EI) and a growing awareness of the benefits it gives to organizations and personal lives, and it's capability to reduce stress. There are many self-development training courses advertised on the internet claiming to be able to improve EI - a simple search on Google will reveal this. However, little research has been conducted to show whether, the tools utilized in such training, can improve EI. Neuro Linguistic Programming (NLP) has often been touted as a powerful technology for engineering change and self-development - in fact, some websites claim that NLP training can improve EI, but without providing proof in the form of research published in peer reviewed journals. The research question is whether the relevant NLP techniques can improve EI scores of participants.

\section{Literature review}

\section{Emotional Intelligence and NLP}

There are many ways of conceptualizing EI, and an exhaustive review is not done here. The three theories that have generated the most interest regarding academic research and practical applications are the theories of BarOn (1988, 2006), Mayer and Salovey (1997), and Goleman (1998). Bar-On (1988), in his doctoral dissertation, coined the term "emotional quotient" (EQ), as an analogy to the intelligence quotient (IQ). Bar-On (1997) defined his model using five main social and emotional abilities including stress management and mood, intrapersonal skills, interpersonal skills, adaptability. These in combination, influence a person's ability to cope effectively with environmental demands. His model framed EI in the context of personality theory, psychological well-being, and adaptation (Goleman, 1998).

Mayer and Salovey (1997) on the other hand viewed EI within a model of intelligence. They argued that traditional measures of intelligence failed to take into account, that different people have different abilities to perceive, process and effectively managing emotions. Mayer and Salovey (1993) proposed that EI is made up of distinct skills, which can be improved by training. Mayer \& Salovey (1993, pg. 433) defined EI is "the ability to monitor one's own and others' emotions, to discriminate among them, and to use the information to guide one's thinking and actions." Their model frames EI from the developmental point of view, and it comprises of four tiers of abilities with the complexity of emotional skill increasing from basic emotional perception to more complex processes integrating emotion and cognition.

Goleman (1998) on the other hand presented an EI based theory of performance, which is competency based and this is what differentiates him from Bar-On (1988) and Mayer and Salovey (1997). Goleman (1998) identified five dimensions of emotional intelligence, which are:

1. Self-awareness - the ability to know one's emotions, strengths, weaknesses, drives, values, and goals and recognize their impact on others while using gut feelings to guide decisions.

2. Self-regulation - involves controlling or redirecting one's disruptive emotions and impulses and adapting to changing circumstances.

3. Self-motivation - being driven to achieve for the sake of achievement.

4. Empathy - considering other people's feelings especially when making decisions and

5. Social skill - managing relationships to move people in the desired direction

These are classified into two broad categories, namely personal competence in dealing with one's self, and social competence in dealing with others (Goleman, 1998). Given the accumulating evidence suggesting the importance of EI competencies for effective work performance, we have adopted Goleman's (1998) model in so far as the operationalization of the EI dimensions is concerned. Furthermore, many studies have shown a significant correlation between EI dimensions as measured by Goleman (1998) and favorable work outcomes. Mayer and Salovey's (1997) idea that EI is something that can be developed and improved is also adopted in this study, but without the operationalization of the distinct levels as proposed by them. Rather, this research views that EI has several dimensions, which can all be improved by training, consistent with the general idea espoused by Mayer and Salovey (1997) and the refinement by Goleman (1998).

2523-6547 - Copyright: (C) 2017 The Authors. This is an open access article distributed under the terms of the Creative Commons Attribution License, which permits unrestricted use, distribution, and reproduction in any medium, provided the original author and source are credited 


\section{What is NLP?}

NLP is about understanding the structure of subjective experience, i.e., how people process information and then using that knowledge to improve performance in others (Einspruch \& Forman, 1985). NLP is eclectic, in that it utilizes many tools drawn from a wide range of sources (Tosey \& Mathison, 2003; 2010). NLP was founded in 1975 by Richard Bandler, a mathematician and John Grinder, a linguist, who argued that NLP is a powerful technology for engineering change (Bandler \& Grinder, 1975; Grinder \& Bandler, 1981). The basic premise of NLP is modeling which is identifying the specific sequence of thoughts and behavior in one person and teaching that structure to another person (Dilts, Grinder, Bandler, Cameron-Bandler, \& DeLozier, 1980). Using the modeling processes, Bandler and Grinder together successfully elicited the critical patterns used by Milton Erickson, Virginia Satir, Fritz Perls, and taught them to others. NLP is therefore often described as a 'study of human excellence' and 'the difference that makes a difference' (Andreas \& Faulkner, 1994). In short, NLP can be regarded as a toolbox that contains many tools and techniques, such as visualization, mental manipulation, and body language techniques, that can be chosen for various situations and concerns. Further description of the NLP techniques chosen for this study is found in the methodology section.

\section{EI and NLP as stress coping mechanisms}

EI training has also been shown improve health and well-being (Slaski \& Cartwright, 2003) and the ability to cope with stress (Croucher, Sohanpal, Muirhead \& Seymour, 2004). Similarly, NLP can be used widely in health care settings (Henwood \& Lister, 2007). Wei, Ku, Russell, Mallinckrodt, and Liao (2008) examined three coping strategies about stress: reflective, suppressive and reactive. Examples of reflective styles are planning and thinking ahead -activities the enable one to anticipate and prepare for problems before they arise, which resembles the value elicitation and goal setting exercise in NLP. The suppressive style of coping involves suppressing the problem, and in some extremes, being in denial of the problem. Suppressive style, which ignores or denies the existence of the problem, is not congruent with the philosophy of NLP. On the contrary, NLP advocates that one must uncover and treat the problem at its source. Reactive style of coping is the tendency to have strong emotional responses, impulsivity, and cognitive confusion often worsening the problem. NLP techniques, on the other hand, equip people with tools to handle the emotional challenges when faced with problems.

There are many similarities between NLP and 'The Ways of Coping Questionnaire' (WCQ: Folkman \& Lazarus, 1988; recently used by Sinha \& Watson, 2007). The WCQ yields eight scores, namely, confronting coping (aggressively trying to change the stressful situation), distancing, self-controlling, seeking social support, accepting responsibility, escape-avoidance, problem-solving and positive reappraisal. Distancing, and selfcontrolling, are the rationales behind the dissociative technique in NLP. Positive reappraisal and accepting responsibility are the prerequisites for the value elicitation and goal setting in NLP. Social support and NLP rapport can be seen to be related to one another. Thus it would be reasonable to argue that NLP techniques are implementation tools for the WEQ, where the primary aim is to reduce stress. Since EI is negatively related to stress, and NLP techniques can help one to cope with stress, then it would also be reasonable to propose that NLP techniques can help improve EI. The challenge would be to select the relevant technique(s) in NLP to improve the relevant dimension of EI.

\section{NLP techniques which can improve EI}

NLP has many techniques designed to improve self-confidence. In conjunction with the EI dimensions, the researcher chose the following NLP techniques (indicated in parentheses), for this study:

i) Self-Awareness (values hierarchy and goal setting)

ii) self-regulation (dissociative technique)

iii) self-motivation (associative technique)

iv) empathy (matching and mirroring)

v) social skills (rapport)

The NLP techniques are described in more detail under the heading of instructions and the reasons for their selection would be obvious from their descriptions.

2523-6547 - Copyright: (C) 2017 The Authors. This is an open access article distributed under the terms of the Creative Commons Attribution License, which permits unrestricted use, distribution, and reproduction in any medium, provided the original author and source are credited 


\section{Justification for more research in NLP}

Academic research into NLP is few and far between, with virtually no recent publication affirming its effectiveness (Tosey \& Mathison, 2003), until the study by Ahmad (2011). Rather, previous studies from the 1980s and early 1990s attempted to debunk it (Dorn, Brunson, \& Atwater, 1983; Poffel \& Cross, 1985; Baddeley \& Predebon, 1991). Heap (1988) and Sharpley (1984) conducted several studies to test the NLP eye movement' model and the notion of 'primary representational system,' where individuals have a preferred sensory mode according to Grinder \& Bandler (1976). The outcomes of the test groups in these studies were no different from that of the control groups. Consequently, Heap (1988) and Sharpley (1984) concluded that NLP could not be accepted. However, Einspruch and Forman (1985) defended NLP and instead, attacked previous research stating that such 'failed' research (as many as thirty-nine separate experimental studies) used flawed methodologies such as using researchers who are not properly trained and certified in NLP. One of the studies cited was Dowd and Hingst's (1983), where students who had no experience as therapists were trained in four 90-min sessions before conducting the experiments. In contrast, a person would have to have approximately 130 hours to be certified at the Practitioner level (and more if he/she were to proceed to the Masters and Trainers level). Topics in NLP, just like in Management, are inter-related. Just as learning one topic in Management does not make one a manager, learning one NLP topic or technique in isolation does not render one proficient in NLP, as there are other skills (such as establishing rapport) which are also necessary as a prerequisite. Rapport is not just about matching representational systems (e.g., visual, auditory or kinaesthetic), but is more complex requiring one to match and mirror many other aspects such as voice qualities ( volume, tonality, speed) and even body posture, facial expressions, and breathing. Einspruch and Forman (1985) pointed out that many previous studies such as Brockman (1981), Green (1981), Paxton (1981), Falzett (1981), Ellickson (1981; 1983), Dowd and Pety (1982), Appel (1983), Cody (1983), Dorn (1983), Ehrmantraut (1983), and Hammer (1983) failed to understand that NLP requires the cooperation and submission of the respondent, which can be obtained by the proper use of rapport. Einspruch and Forman (1985) aptly pointed out that if comparisons are to be made with other treatment approaches, the researchers conducting the experiments in NLP must have the necessary qualifications as proof of proficiency - one cannot simply attend one or two workshops, read a book and assume that he or she can effectively perform NLP therapy any more than this can be assumed for any other model of therapy. In contrast, the researcher in the current study has been a Trainer of NLP for several years.

Although Einspruch and Forman (1985) defended NLP by attacking the multitude of previous research that attempted to debunk it, however, they have failed to conduct any experiments to validate any of the NLP techniques. This daunting task was taken up by Ahmad (2011) who looked at the effectiveness of the alternative techniques of NLP, Time Line Therapy ${ }^{\circledR}$, and Hypnosis as means of reducing the intensity of negative emotions associated with memories of stressful events. In an experimental research that involved 32 test subjects and 32 control group subjects, statistical t-tests revealed that there were significant reductions in intensity levels of negative emotions after undergoing the procedures compared with before, with the test group whereas there were no significant changes in the control group. This was true for all three methods. Currently, this is one of the most convincing research publications about the effectiveness of the dissociative method - one of the many techniques in NLP. However, there are two limitations of the study: firstly, most of the respondents were self-selected, and secondly, other NLP techniques were not examined. Both of these problems were avoided in the current study.

From the literature review above, the following hypotheses were developed:

H1: The NLP techniques of values hierarchy and goal setting can improve the self-awareness dimension of EI.

\section{H2: The NLP dissociative techniques can improve the self-regulation dimension of EI.}

\section{H3: The NLP associative technique can improve the self-motivation dimension of EI.}

\section{H4: The NLP techniques of matching and mirroring can improve the empathy dimension of EI.}

\section{H5: The NLP rapport technique can improve the social skills dimension of EI.}

More detailed description of the techniques is given in the methodology section below.

2523-6547 - Copyright: (C) 2017 The Authors. This is an open access article distributed under the terms of the Creative Commons Attribution License, which permits unrestricted use, distribution, and reproduction in any medium, provided the original author and source are credited 


\section{Method}

\section{The measures}

There are many multi-item measures of EI, and the proponents of each version will claim that the construct validity of their questionnaire is higher than others. Rather, the approach taken in this study was to focus on the face validity of the questions and to make things as simple as possible for the respondents. Consequently, each EI dimension was measured by using the definition of the dimension itself, i.e., only one item as shown below. As comparable studies have shown that one-item measures of satisfaction are strongly correlated with more complex multidimensional measures of satisfaction (Ahmad, 2001), by analogy, the same could be argued for the case of EI. The items were as follows:

1) Self-awareness: "I am aware of myself as a person regarding my character, strengths, weakness, drives values and goals, and how they impact others."

2) Self-regulation: "I can control or redirect disruptive emotions and impulses while adapting to changing circumstances."

3) Self-motivation: "I know how to, and can motivate myself to achieve for the sake of achievement."

4) Empathy: "I can know how others are feeling, especially when making decisions."

5) Social skill: "I can manage my relationships with others and to move people in the desired direction."

These items were scored on a 5 point Likert scale ranging from strongly disagree (1) to strongly agree (5). Participants filled the questionnaires before, as well as immediately after, the training session.

\section{The sample}

Respondents in the test group were 35 participants from two separate sessions. Both sessions were identical and conducted personally by the researcher. Respondents were selected using the random assignment as follows: the researcher first prepared a sampling frame from the list of classes in postgraduate business studies taught by the researcher at a University. One of the conditions is that the class must have the maximum number of 35 students. One class was treated as the test group, and the other class was treated as a control group. This ensured that the test group is comparable (although not exactly identical) with that of the subject group (Zikmund, Babin, Carr \& Griffin, 2010) since both are graduate classes of business at the same university. The sample consists of 35 participants in the test group and 35 participants in the control group.

The control group has roughly the same mean age as the test group, which is 38 years. The age range in the control group was 28-47 years, but the age range in the test group was 26-45 years. There are also similarities regarding gender composition (i.e., 17 males and 18 females in the test groups and also 19 males and 16 females in the control group). In terms of number of subjects in test groups and control groups, this research is superior to others (one test person and no control group in Ewin, 2004; eight female patients and no control group in Keefer \& Keshavarzian, 2007; 22 test groups and 22 control groups in Shakibaei, Harandi, Gholamrezaei, Samoei, \& Salehi, 2008).

The respondents in the test group filled out the questionnaire twice, i.e., immediately before the procedure and immediately after. Although the researcher played the role of both facilitator and researcher, objective scoring was used to minimize researcher bias. Furthermore, there was no data collected by the researcher's observation. Instead, the respondents filled out the questionnaires themselves, and their scores were directly entered into the Statistical Package for Social Sciences (SPSS) program by a research assistant and without any transformation whatsoever by the researcher. Experimenter bias is reduced by ensuring that the questionnaires were distributed and collected by a research assistant and in the absence of the researcher.

The respondents in the control group filled out the questionnaire twice. The period between filling-up the questionnaires was two and a half hours which is approximately how long the test group took to do the activities. The control group was not taught any NLP techniques during this period - instead, they were taught a lesson on SPSS.

This research was conducted in a country where no prior ethics approval is required for a study of this kind. The participants also verbally consented to participating in this research at the beginning of the seminar and subsequently filled out all the questionnaires.

\section{Instructions}

2523-6547 - Copyright: (C) 2017 The Authors. This is an open access article distributed under the terms of the Creative Commons Attribution License, which permits unrestricted use, distribution, and reproduction in any medium, provided the original author and source are credited 


\section{The value hierarchy and goal setting (in conjunction with EI dimension of self-awareness)}

Participants of the seminar were instructed to list what is important to them (i.e., their values) and then give them a ranking. Coaching, guidance, and assistance were given to the participant respondents during the session. They are also trained how to formulate "SMART" goals, but with finer distinctions in line with the NLP philosophy. For instance, the goals have to be positively stated, i.e., what they want (as opposed to negative, i.e., what they don't want) and expressed in the present tense (as opposed to the past or future tense).

\section{Dissociative technique (in conjunction with EI dimensions of self-regulation)}

About self-regulation, the participants were asked to remember an event that they still felt stressed about. Then, they were taught the dissociative technique used by Ahmad (2011), i.e., see through the third person view. Then, they were asked to change the 'submodalities' of the mental picture by changing it from color to black and white, reducing the clarity and size and gradually pushing the picture further and further away from them.

\section{Associative technique (in conjunction with EI dimension of self-motivation)}

About self-motivation, participants are asked to think about the task or activity that they want to feel more motivated. Then they did the opposite of what they had done earlier, i.e., they were asked to imagine it vividly and associate themselves with the memory, which is, see through the first person view by looking through their own eyes and not seeing their body in the picture. Then, they were asked to change the 'submodalities' of the mental picture by increasing the color, brightness, clarity, and size and gradually bringing the picture closer and closer towards them.

\section{Matching and mirroring technique (in conjunction with EI dimensions of empathy)}

The participants were first taught how to match and mirror the body posture and facial expressions of others. Matching simply means that one is imitating the body posture, facial expressions and voice qualities of others. The difference between matching and mirroring is, in matching, if the other person has his/her right arm raised, you also raise your right arm. In mirroring, if the person directly opposite and facing you has his/her right arm raised, you raise your left arm.

Participants were told to assemble in groups of three. In each group, one person plays the role of the observed, the other the person who matches and mirrors. The third person plays the role of third-party observer, who observes the other two, and makes fine adjustments to the matcher/mirror so that he/she exactly matches/mirrors the observed. The person who matches/ mirrors, then have to guess what the person being observed, is thinking and feeling.

\section{Rapport (in conjunction with social skills)}

The participants were taught not only how to match and mirror the body posture and facial expressions of others, but also their voice qualities (volume, pitch, tempo, timbre and key words). The class was divided into two groups. In both groups, participants were asked to form pairs. In the first group, one person talks while the other listens and deliberately does not match and mirror. For the other group, one person talks while the other listens and matches or mirrors the other. This was done for five minutes. For both groups, the instructor then asks the people who were doing the talking whether they felt connected with the listeners. It was found that rapport exists much more in groups where the listener matches or mirrors the talker, compared with groups where the listener does not.

2523-6547 - Copyright: (C) 2017 The Authors. This is an open access article distributed under the terms of the Creative Commons Attribution License, which permits unrestricted use, distribution, and reproduction in any medium, provided the original author and source are credited 


\section{Results}

Paired samples T-Test were conducted and results showed that there were significant increases in the mean values of the relevant dimensions of EI after the NLP activities, compared with before. Overall, the NLP techniques chosen for this study managed to increase the EI scores for each dimension, thus improving the total EI scores of the test subjects. In contrast, the control group had no changes in EI scores.

Table 1: Mean scores of test group of respondents before and after the NLP training

\begin{tabular}{|c|c|c|c|c|}
\hline $\begin{array}{c}\text { EI } \\
\text { dimension }\end{array}$ & NLP technique & $\begin{array}{l}\text { Mean scores before } \\
\text { NLP activity }\end{array}$ & $\begin{array}{l}\text { Mean scores before } \\
\text { NLP activity }\end{array}$ & Significance \\
\hline $\begin{array}{c}\text { self- } \\
\text { awareness }\end{array}$ & $\begin{array}{l}\text { values hierarchy and } \\
\text { goal setting }\end{array}$ & 4.8 & 6.5 & Sig \\
\hline $\begin{array}{l}\text { self- } \\
\text { regulation }\end{array}$ & dissociative technique & 4.7 & 7.6 & Sig \\
\hline $\begin{array}{c}\text { self- } \\
\text { motivation }\end{array}$ & associative technique & 4.8 & 7.6 & Sig \\
\hline empathy & matching and mirroring & 4.9 & 5.7 & Sig \\
\hline social skills & rapport & 4.9 & 6.8 & Sig \\
\hline
\end{tabular}

\section{Conclusion}

This study examined the effectiveness of selected NLP techniques as means of improving EI scores. The sample consisted of 35 individuals in the test groups and 35 individuals in the control group. Measurements were taken before and after each of the procedures. Overall, the NLP techniques chosen for this study managed to increase the EI scores for each dimension, thus improving the total EI scores of the test subjects. In contrast, the control group had no changes in EI scores. This suggests that NLP techniques are effective and are responsible for these changes.

Some respondents reported more favorable experiences with some of the techniques compared with others. Among the favorites are the associative and dissociative techniques to improve the self-motivation and selfregulation dimensions of EI, respectively. The least favorite technique was the NLP matching and mirroring which was used to improve the empathy dimension. Some groups reported outstanding success with such techniques and reported high scores after the techniques. But many groups were unable to read others emotions using this technique, resulting in a lack of confidence in this technique and therefore reported lower scores. The values hierarchy was popular among participants (according to their verbal reports), but because that technique was taught together with goal setting techniques (which many are already familiar with), the overall increase in scores was less compared with the associative and dissociative techniques.

In the current study, the final sample consisted of students in the randomly picked class. Although the researcher conducted the experiments, this introduces no more bias than surveys since the data collected in this research was not through the researcher's observations (which could potentially introduce bias and is thus objectionable) but thru self-administered questionnaires with objective scoring. Objective scoring per se (unlike data collection by observation) introduces no bias because the scores would be the same if it were compiled by another person. It is worth pointing out that in this study, the questionnaires were distributed, collected and compiled by a research assistant. Demand effects and experimenter bias are reduced by not telling the subjects of the experimental hypotheses (i.e., whether NLP techniques can improve EI) but just simply teach them the techniques.

However, there is still a limitation in this study in that there is no way of knowing whether the increases in EI scores as a result of training in NLP techniques are permanent or temporary. Future research could take the form of a longitudinal study spread over a year and measurements can be taken in one, three, six months, and one year

2523-6547 - Copyright: (C) 2017 The Authors. This is an open access article distributed under the terms of the Creative Commons Attribution License, which permits unrestricted use, distribution, and reproduction in any medium, provided the original author and source are credited 
into the future. However, it is difficult to control all the extraneous variables that exist in a field setting, such as traumatic life changing events and whether the test subjects continue to practice the NLP techniques. This is something that exists in other experimental studies such as Ewin, 2004; Keefer \& Keshavarzian, 2007; Shakibaei, Harandi, Gholamrezaei, Samoei, \& Salehi, 2008. Lastly, data were obtained through self-report instruments. The limitations that apply to self-report questionnaires, such as compliance bias, have the potential to be present in this research, just as it has the potential to be present in all other research using self-report measures. 


\section{Bibliography}

Ahmad, K. Z. (2001). The Association between Person, Work Environment, Job Satisfaction and Performance: A study in light manufacturing assembly plants. Unpublished PhD thesis, University of Manchester Library.

Ahmad, K. Z. (2011). Alternatives to simply forgiving and forgetting: examining techniques in hypnosis, NLP and Time Line Therapy in reducing the intensity of negative emotions attached to memories of stressful events. Stress and Health, 27(3), 241-250.

Andreas, S., \& Faulkner, C. (1994). NLP - The New Technology of Achievement. New York: William Morrow.

Appel, P. (1983). Matching representational systems and interpersonal attraction. United States International University, Dissertation Abstracts International 43, 3021B: (University Microfilms No 83-018, 35).

Baddeley, M., \& Predebon, J. (1991). 'Do the eyes have it?': A test of neurolinguistic programming's eyemovement hypothesis. Australian Journal of Clinical Hypnotherapy and Hypnosis, 12(1), 1-23.

Bandler, R., \& Grinder, J. (1975). The structure of magic I: A book about language and therapy. Palo Alto, CA: Science and Behaviour Books.

Bar-On, R. (1988). The development of a concept of psychological well-being. Unpublished doctoral dissertation, Rhodes University: South Africa.

Bar-On, R. (1997). The Emotional Quotient Inventory (EQ-I): a test of emotional intelligence. Toronto: MultiHealth Systems.

Bar-On, R. (2006). The Bar-On model of emotional-social intelligence (ESI). Psicothema, 18, supl., 13-25.

Brockman, W. (1981). Empathy revisited: The effect of representational system matching on certain counselling process and outcome variables. (Doctoral dissertation, College of William and Mary). Dissertation Abstracts International, 41, 3421A: (University Microfilms No. 81-035, 91).

Cody, S. G. (1983). The stability and impact of the primary representational system in Neurolinguistic Programming: A critical examination. (Doctoral dissertation, University of Connecticut). Dissertation Abstracts International, 44, 1232B: (University microfilms No. 83-191, 87).

Croucher, R., Sohanpal, R., Muirhead, V., \& Seymour, K. (2004). Emotional intelligence and stress coping in dental undergraduates - a qualitative study. British Dental Journal, 197, 205-209.

Dilts, R., Grinder, J., Bandler, R., \& Delozier, J. (1980). Neuro-linguistic programming (Vol. 1), The study of the structure of subjective experience. Capitola, CA: Meta Publications.

Dorn, F. J. (1983). The effects of counsellor-client predicate use in counsellor attractiveness. American Mental Health Counselor's Association Journal, 5, 22-30.

Dorn, F. J., Brunson, B. I., \& Atwater, M. (1983). Assessment of primary representational systems with neurolinguistic programming: examination of preliminary literature. American Mental Health Counsellors Journal, 5(4), 161-168.

Dowd, E., \& Hingst, A. (1983). Matching therapists' predicates: An in vivo test of effectiveness. Perceptual and Motor Skills, 57, 207-210.

Dowd, E., \& Petty, J. (1982). Effect of counsellor predicate matching on perceived social influence and client satisfaction. Journal of Counseling Psychology, 29, 206-209.

2523-6547 - Copyright: (C) 2017 The Authors. This is an open access article distributed under the terms of the Creative Commons Attribution License, which permits unrestricted use, distribution, and reproduction in any medium, provided the original author and source are credited 
Ehrmantraut, J. E. (1983). A comparison of the therapeutic relationship of counselling students trained in neurolinguistic programming vs students trained in the Carkuff model. (Doctoral dissertation Abstracts International, 44, 3191B): (University Microfilms No. 83-284,91).

Einspruch, E. L., \& Forman, B. D. (1985). Observations concerning research literature on Neuro Linguistic Programming. Journal of Consulting Psychology, 32(4), 589-596.

Ellickson, J. (1981). The effect of interviewers responding differentially to participants' eye movement. (Dissertation Abstracts International, 41, 2754B). (University Microfilms No.81-01,102).

Ellickson, J. (1983). Representational systems and eye movements in an interview. Journal of Counseling Psychology, 30, 339-345.

Ewin, D. M. (2004). Single-visit hypnotic cure of stentorian snoring: a brief communication. International Journal of Clinical and Experimental Hypnosis, 52(4), 400-403.

Falzett, W. (1981). Matched versus unmatched primary representational systems and their relationship to perceived trustworthiness in a counselling analog. Journal of Counseling Psychology, 28, 305-308.

Folkman, S., \& Lazarus, R. S. (1988). Manual for the Ways of Coping Questionnaire: Research edition. Palo Alto, CA: Consulting Psychologists Press.

Goleman, D. (1998). Working with emotional intelligence. New York: Bantam Books.

Goleman, D. (1998). Working with Emotional Intelligence. Bantam Books.

Green, M. (1981). Trust as affected by representational system predicates. (Doctoral dissertation, Ball State University, 1979). Dissertation Abstracts International, 41, 3159B-3160B: (University Microfilms No. 81-046, 51).

Grinder, J., \& Bandler, R. (1976). Patterns of the Hypnotic Techniques of Milton H. Erickson, M.D. Volume I. Cupertino, CA: Meta Publications.

Grinder, J., \& Bandler, R. (1981). Trance-formations. Moab, UT: Real People Press.

Hammer, A. (1983). Matching perceptual predicates: Effect on perceived empathy in a counselling analog. Journal of Counseling Psychology, 30, 172-179.

Heap, M. (1988). Neurolinguistic programming - an interim verdict. In M. Heap (Ed.), Hypnosis: Current clinical, experimental and forensic practices (pp. 268-280). London: Croom Helm.

Henwood, S., \& Lister, J. (2007). NLP and Coaching for Health Care Professionals: Developing Expert Practice. Chichester, West Sussex, England: John Wiley \& Sons Ltd.

Keefer, L., \& Keshavarzian, A. (2007). Feasibility and acceptability of gut directed hypnosis on inflamatory bowel disease: A brief communication. International Journal of Clinical and Experimental Hypnosis, 55(4), 457-466.

Mayer, J. D., \& Salovey, P. (1993). The intelligence of emotional intelligence. Intelligence, 17(4), 433-442.

Mayer, J. D., \& Salovey, P. (1997). What is emotional intelligence? In P. Salovey, \& D. Sluyter (Eds.), Emotional development and emotional intelligence: implications for educators (pp. 3-31). New York: Basic Books.

Paxton, L. (1981). Representational systems and client perception of the counselling relationship. (Doctoral dissertation, Indiana University, 1980). Dissertation Abstracts International, 41, 3888A: (University Microfilms No. 81-059, 41).

Poffel, S. A., \& Cross, H. J. (1985). Neurolinguistic programming: A test of the eye-movement hypothesis. Perceptual and Motor Skills, 61(3), 12-62.

2523-6547 - Copyright: (C) 2017 The Authors. This is an open access article distributed under the terms of the Creative Commons Attribution License, which permits unrestricted use, distribution, and reproduction in any medium, provided the original author and source are credited 
Shakibaei, F., Harandi, A. A., Gholamrezaei, A., Samoei, R., \& Salehi, P. (2008). Hypnotherapy in management of pain and reexperiencing trauma in burn patients. International Journal of Clinical and Experimental Hypnosis, 56(2), 185-197.

Sharpley, C. (1984). Predicate matching in NLP: A review of research on the preferred representational system. Journal of Counseling Psychology, 31, 238-248.

Sinha, B. K., \& Watson, D. C. (2007). Stress, coping and psychological illness: a cross cultural study. International Journal of Stress Management, 14(4), 386-397.

Slaski, M., \& Cartwright, S. (2003). Emotional intelligence training and its implications for stress, health and performance. Stress and Health, 19(4), 233-239.

Tosey, P., \& Mathison, J. (2003). Neuro-linguistic programming and learning theory: A response. The Curriculum Journal, 14(3), 361-378.

Tosey, P., \& Mathison, J. (2010). Neuro-Linguistic programing as an innovation in education and teaching. Innovations in Education and Teaching International, 47(3), 317-326.

Wei, M., Ku, T. Y., Russell, D. W., Mallinckrodt, B., \& Liao, K. Y. (2008). Moderating effects of three coping strategies and self-esteem on perceived discrimination and depressive symptoms: A mnoirty stress model for Asian international students. Journal of Counseling Psychology, 55(4), 451-462.

Zikmund, W. G., Babin, B. J., Carr, J. C., \& Griffin, M. (2010). Business Research Methods (8th ed.). SouthWestern: Cengage Learning.

Table 1: T-Tests of EI scores before and after NLP training

\begin{tabular}{lllll}
\hline EI dimension & NLP technique & $\begin{array}{l}\text { Mean scores before } \\
\text { NLP activity }\end{array}$ & $\begin{array}{l}\text { Mean scores before } \\
\text { NLP activity }\end{array}$ & Significance \\
\hline self-awareness & $\begin{array}{l}\text { values hierarchy } \\
\text { and goal setting }\end{array}$ & 4.8 & 6.5 & Sig \\
self-regulation & $\begin{array}{l}\text { dissociative } \\
\text { technique }\end{array}$ & 4.7 & 7.6 & Sig \\
self-motivation & $\begin{array}{l}\text { associative } \\
\text { technique }\end{array}$ & 4.8 & 7.6 & Sig \\
empathy & $\begin{array}{l}\text { matching and } \\
\text { mirroring }\end{array}$ & 4.9 & 5.7 & Sig \\
social skills & rapport & 4.9 & 6.8 & Sig \\
\hline
\end{tabular}

2523-6547 - Copyright: (C) 2017 The Authors. This is an open access article distributed under the terms of the Creative Commons Attribution License, which permits unrestricted use, distribution, and reproduction in any medium, provided the original author and source are credited 
2523-6547 - Copyright: (C) 2017 The Authors. This is an open access article distributed under the terms of the Creative Commons Attribution License, which permits unrestricted use, distribution, and reproduction in any medium, provided the original author and source are credited 